\title{
Pharmacokinetics and Pharmacodynamics of
}

\section{Dexmedetomidine Administered as an Adjunct to} Bupivacaine for Transversus Abdominis Plane Block in Patients Undergoing Lower Abdominal Cancer Surgery

\author{
Fatma A El Sherif' \\ Hala Abdel-Ghaffar ${ }^{2}$ \\ Ahmed Othman (D)' \\ Sahar Mohamed \\ Mervat Omran ${ }^{3}$ \\ Samia Shouman (1D) \\ Nivin Hassan ${ }^{5}$ \\ Ayat Allam ${ }^{6-8}$ \\ Sahar Hassan 9
}

\begin{abstract}
'Anesthesia, Intensive Care and Pain Management Department, South Egypt Cancer Institute, Assiut University, Assiut, Egypt; ${ }^{2}$ Anesthesia and Intensive Care Department, Faculty of Medicine, Assiut University, Assiut, Egypt; ${ }^{3}$ Cancer Biology Department (Pharmacology and Experimental Oncology), National Cancer Institute, Cairo University, Cairo, Egypt;

${ }^{4}$ Cancer Biology Department, National Cancer Institute, Cairo University, Cairo, Egypt; ${ }^{5}$ Cancer Biology Department (Pharmacology and Experimental Oncology), South Egypt Cancer Institute, Assiut University, Assiut, Egypt; ${ }^{6}$ Pharmaceutics Department, Faculty of Pharmacy, Assiut University, Assiut, 7I5I5, Egypt; ${ }^{7}$ Pharmaceutics Department, Faculty of Pharmacy, Sphinx University, New Assiut City, Egypt; ${ }^{8}$ Assiut International Center of Nanomedicine, AL-Rajhy Liver Hospital, Assiut University, Assiut, 7I5I5, Egypt; ${ }^{9}$ Clinical Pharmacy Department, Faculty of Pharmacy, Assiut University, Assiut, Egypt
\end{abstract}

Correspondence: Ahmed Othman

Tel +20 1005098394

Fax +20882086609

Email ahmadhothman@gmail.com
Background: Despite the growing interest in dexmedetomidine as an adjunct to truncal blocks, little is known about the systemic absorption of dexmedetomidine after these blocks and its role in analgesia and in hemodynamics.

Objective: We investigated the pharmacokinetics and pharmacodynamics of dexmedetomidine as an adjunct to transversus abdominis plane (TAP) block in patients undergoing lower abdominal cancer surgery.

Methods: Twenty-four adult patients were randomized to receive a bilateral singleinjection TAP block before surgery with $20 \mathrm{~mL}$ of bupivacaine $0.5 \%$ (TAP group, $\mathrm{n}=$ 12) or combined with $1 \mu \mathrm{g} / \mathrm{kg}$ dexmedetomidine (TAP-DEX group, $\mathrm{n}=12$ ) and diluted with saline to a volume of $40 \mathrm{~mL}$ (20 mL on each side). Plasma concentrations of dexmedetomidine and its pharmacokinetics were investigated using non-compartmental methods, postoperative analgesia, hemodynamics, and adverse events (nausea, vomiting, itching, hypotension, bradycardia, and respiratory depression).

Results: Dexmedetomidine was detected in the plasma of 11 patients in the TAP-DEX group. The mean dexmedetomidine peak plasma concentration (Cmax) was $0.158 \pm 0.085$ (range, $0.045-0.31) \mathrm{ng} / \mathrm{mL}$. The median time to reach peak plasma concentration of dexmedetomidine (Tmax) was $15(15-45)$ min. From 2 to $8 \mathrm{~h}$ postoperatively, visual analog pain scale (VAS) scores at rest and during movement were significantly lower in the TAP-DEX group. Analgesia time was $(11.3 \pm 3.12$ vs $9.0 \pm 4.69 \mathrm{~h} ; \mathrm{P}=0.213)$ and postoperative morphine consumption was $(7.4 \pm 3.24$ vs $11.5 \pm 4.46 \mathrm{mg} ; \mathrm{P}=0.033)$ in TAP-DEX and TAP groups, respectively. Lower mean heart rate and mean blood pressure were recorded in the TAP-DEX group intraoperatively and $2 \mathrm{~h}$ postoperatively $(\mathrm{P}<0.05)$. Except for mild nausea and vomiting, no adverse events were recorded in either group.

Conclusion: Systemic absorption of dexmedetomidine administered in a TAP block is common. Direct central effects on the locus coeruleus caused by this systemic absorption may play a role in the analgesia and hemodynamic effects produced by TAPdexmedetomidine in addition to local mechanisms.

Trial Registration: ClinicalTrial.gov (identifier: NCT03328299).

Keywords: analgesia, transversus abdominis plane block, dexmedetomidine, pharmacokinetics, pharmacodynamics 


\section{Introduction}

Since originally described by Rafi et al in 2001, the transversus abdominis plane (TAP) block has undergone various modifications in technique, approaches, and local anesthetic regimens. ${ }^{1}$ The main issue is that it provides somatic analgesia to the anterior abdominal wall through a non-dermatomal field block achieved by injecting a relatively large volume of local anesthetic into the fascial plane between the internal oblique and transversus abdominis muscles. ${ }^{2}$ It anesthetizes the spinal nerves from the 7th to 12 th, the ilio-inguinal and ilio-hypogastric nerves. ${ }^{2}$

Compared to local anesthetic wound infiltration, TAP block significantly decreased pain scores and opioid consumption after abdominal surgery. ${ }^{3}$ Although not superior to epidural analgesia, TAP block has the advantage of being less invasive and is associated with a lower incidence of hypotension and shorter hospital stay. ${ }^{4,5}$ Clinicians frequently add different adjuvants to local anesthetics to prolong the duration of single-injection TAP block analgesia. ${ }^{6-8}$

Dexmedetomidine, a highly selective $\alpha-2$ receptor agonist, is commonly used off-label as an adjuvant to singleinjection perineural peripheral nerve blocks, such as the brachial plexus block, ${ }^{9}$ and truncal blocks, such as the TAP block. ${ }^{6}$ The addition of dexmedetomidine increased the duration of the block and reduced postoperative pain scores and opioid consumption, compared to local anesthetics alone. ${ }^{10,11}$ Intravenous and perineural dexmedetomidine has been found to also prolong the duration of analgesia after peripheral nerve blocks. ${ }^{12-14}$ The exact mechanism of action of perineural dexmedetomidine is unclear; it may occur partly due to peripheral perineural mechanisms or due to central effects on the locus coeruleus from systemic absorption of the drug. ${ }^{15,16}$

Despite the growing interest in dexmedetomidine as an adjunct to truncal and peripheral nerve blocks, little is known about the systemic concentrations of dexmedetomidine after these blocks. This study aimed to investigate the pharmacokinetics and pharmacodynamics of dexmedetomidine on postoperative analgesia, hemodynamics, and adverse events as an adjunct to single-injection TAP block in patients undergoing lower abdominal cancer surgery.

\section{Patients and Methods}

\section{Ethical Considerations, Eligibility, and Study Design}

This prospective randomized, double-blind clinical controlled study was approved by the Research Ethics
Committee, South Egypt Cancer Institute, Assiut University, Assiut, Egypt (ID: SECI-IRB/IORG0006563/ no. 402, date; $23 / 10 / 2017$, Head of the Committee; Prof. Ashraf Zydan). Written informed consent was obtained from all study participants. The trial was registered on Clinical Trial. gov. (Identifier: NCT03328299, Principal investigator: Assistant Prof. Fatma Adel El Sherif, first posted: 1/11/2017, study start: 11/11/2017) before the enrollment of the first patient. We strictly followed the regulations and amendments of the Declaration of Helsinki. The patients enrolled in this study were aged 18-60 years, with body mass index (BMI) $\leq 30 \mathrm{~kg} / \mathrm{m}^{2}$, American Society of Anesthesiologists (ASA) I-II, scheduled for lower abdominal cancer surgery (abdominal hysterectomy and radical cystectomy) under a low midline vertical incision, who were scheduled to receive bilateral single-injection TAP block for postoperative analgesia. Exclusion criteria included significant cardiac, respiratory, renal, central nervous system, or hepatic diseases; pregnancy; BMI $\geq 30 \mathrm{~kg} / \mathrm{m}^{2}$; bleeding diathesis, allergy to study drugs, history of drug addiction, and patients with psychiatric illnesses that would interfere with the perception and assessment of pain.

\section{Randomization and Blindness}

Patient randomization was performed using computergenerated randomization tables and group allocation was hidden in sealed opaque envelopes. Twenty-four patients were enrolled in two groups of 12 patients each to receive a bilateral single-injection TAP block with $20 \mathrm{~mL}$ of bupivacaine $0.5 \%$ (Markyrene ${ }^{\mathbb{B}}$ Sigma-Tec, Egypt) (TAP group) or $20 \mathrm{~mL}$ of bupivacaine $0.5 \%$ combined with $1 \mu \mathrm{g} / \mathrm{kg}$ dexmedetomidine (Precedex ${ }^{\circledR}$ Hospira, Inc., Lake Forest, USA) (TAP-DEX group). A physician who was not involved in the study diluted the study drugs with normal saline $0.9 \%$ to a final volume of $40 \mathrm{~mL}$ and a bupivacaine concentration of $0.25 \%$ in identical sterile syringes with matching random codes that were opened before induction of anesthesia. The surgeon, attending anesthesiologists, data collection personnel, and patients were blinded to the group assignment.

\section{Study Protocol}

During the preoperative assessment, patients were instructed on how to express their pain using the visual analog pain scale (VAS) (scored 0-10; 0, no pain and 10, the worst pain imaginable), and how to use the intravenous patient-controlled analgesia (IV-PCA) device. 
In the operating room, monitoring was attached to the patients, including noninvasive arterial blood pressure, electrocardiogram, end-tidal carbon dioxide capnography, and peripheral arterial oxygen saturation. Anesthesia was induced with propofol $2-3 \mathrm{mg} / \mathrm{kg}$, fentanyl $1-2 \mu \mathrm{g} / \mathrm{kg}$, lidocaine $1.5 \mathrm{mg} / \mathrm{kg}$ and $0.6 \mathrm{mg} / \mathrm{kg}$ rocuronium to facilitate endotracheal intubation. After induction of anesthesia and before surgery, all patients received a bilateral ultrasound-guided single-injection TAP block according to the group assignment. The surgery started 15 min after the TAP block was performed. Anesthesia was maintained with isoflurane in a $50 \%$ oxygen/air mixture, and the minimum alveolar concentration (MAC) was titrated in anticipation of the adjuvant effects of the TAP block. Patients were mechanically ventilated in volume cycle mode with ventilation parameters that achieved an $\mathrm{ETCO}_{2}$ of approximately $35-40 \mathrm{mmHg}$. At the end of the surgery, muscle paralysis was reversed with $2 \mathrm{mg} / \mathrm{kg}$ sugammadex IV. The patients were extubated awake and transferred to the surgical intensive care unit (SICU). All patients were connected to an IV-PCA analgesia device (B. Braun Melsungen, Melsungen, Germany) for postoperative analgesia. The IV-PCA solution contained $100 \mathrm{mg}$ of morphine diluted in $100 \mathrm{~mL}$ of normal saline $0.9 \%(1 \mathrm{mg} / \mathrm{mL})$. The IV-PCA program consisted of an initial bolus of morphine $0.1 \mathrm{mg} / \mathrm{kg}$ once the pain was conveyed by the patient or if VAS $\geq 3$ was reported, followed by $1 \mathrm{mg}$ boluses with a 5-min lockout period without continuous background infusion.

\section{The Intervention}

After induction of general anesthesia and before surgery, TAP block was performed by an experienced investigator under dynamic ultrasound guidance with a high-frequency linear ultrasound probe (Sonosite ${ }^{\circledR}$, Inc. USA) and an in-plane $100 \mathrm{~mm}$ 20G needle (Pajunk Sono Plex Stim cannula USA). The ultrasound probe was placed transversely in the midaxillary line between the anterior superior iliac spine and the costal margin. Using real-time ultrasound imaging, the external oblique, internal oblique, and transversus abdominis muscles were identified. After negative aspiration to exclude vascular puncture, a test dose of $1 \mathrm{~mL}$ of saline was injected to open the plane between the two muscles. If the test dose was demonstrated to be within the muscles rather than between them, needle repositioning was required, and the test was repeated. Subsequently, the full dose of the study drug was administered according to group assignment, and the detection of a hypoechoic layer on the ultrasound screen was confirmed. Then, the entire procedure was repeated on the other side. The success of the block was suspected intraoperatively if the patient's hemodynamics did not change significantly with surgical incision and was accurately confirmed postoperatively after full recovery using the pinprick test. Using a sterile needle, the loss of sensation of the abdominal wall was tested through the anatomic distribution of the intercostal nerves from T6 to L1, depending on the standard chart of skin dermatomes. Failed cases were excluded from the study.

\section{Blood Sampling}

Seven whole venous blood samples (3 $\mathrm{mL}$ each) were collected in EDTA tubes. Samples were obtained from the patients at 15,30, and $45 \mathrm{~min}$ and $1,2,4$, and 6 $\mathrm{h}$ after drug administration. Centrifugation at $2500 \times \mathrm{g}$ for $10 \mathrm{~min}$ was performed within $2 \mathrm{~h}$ of sample collection. The resultant plasma was stored at $-80{ }^{\circ} \mathrm{C}$ until assayed.

\section{Sample Extraction and Preparation for Liquid Chromatography-Tandem Mass Spectrometry}

Five hundred microliters of plasma were thoroughly mixed with $1 \mathrm{~mL}$ of a mixture of methanol and acetonitrile $(1: 1, \mathrm{v} / \mathrm{v})$ (Sigma-Aldrich, Steinheim, Germany), vortexes $60 \mathrm{~s}$ and centrifuged at $10,000 \times \mathrm{g}$ for $15 \mathrm{~min}$ at $4{ }^{\circ} \mathrm{C} ; 10 \mu \mathrm{L}$ of the resultant clear supernatant was injected into the $\mathrm{AB}$ SCIEX LC/MS/MS system (AB SCIEX 3200 Q TRAP, Germany) equipped with an electrospray ionization source and an Agilent 1260 affinity high performance liquid chromatography (HPLC) system. The analytical column used was XBridge-C18 $(150 \mathrm{~mm} \times 2.1 \mathrm{~mm} \times 5 \mu \mathrm{m}$, Waters, Ireland $)$ at $25{ }^{\circ} \mathrm{C}$. The mobile phase consists of two parts of $0.1 \%$ formic acid in water (solvent $\mathrm{A}$ ) and one part of a mixture of methanol and acetonitrile $(1: 1, \mathrm{v} / \mathrm{v})$ (solvent $\mathrm{B})$, delivered at a flow rate of $0.3 \mathrm{~mL} / \mathrm{min}$. The Analyst 1.6 software was used for data acquisition and the Multiquant software was used for calculation. Typical chromatograms for dexmedetomidine were detected at $4.4 \mathrm{~min}$ retention time and following ion transition: $\mathrm{m} / \mathrm{z}$ 201.2:95.1, for dexmedetomidine. The standard curve was prepared at concentrations ranging from 0.05 to $12.5 \mathrm{ng} / \mathrm{mL}$ of dexmedetomidine in drug-free plasma and extracted as mentioned in the sample preparation. The calibration curve showed a linear relationship $\left(r^{2} \geq 0.99\right) .{ }^{17}$

\section{Outcome Measurements}

In addition to the patients' demographic and clinical data, including age, weight, and height, the following data were collected: 


\section{Pharmacokinetic Assessments}

Pharmacokinetic parameters were determined using a noncompartmental method with WinNonlin professional version 2.1 software (Pharsight Corporation, Mountain View, CA, USA). The following parameters were calculated for plasma concentrations of dexmedetomidine: area under the concentration-time curve from time zero to the last measurable sampling time point (AUCall) (ng/mL*min), AUC from time zero to time infinity (AUCinf) (ng/mL*min), maximum plasma concentration (Cmax) (ng/mL), time to reach Cmax (Tmax) (min), apparent volume of distribution (V/f) (L), apparent clearance (CL/f) (L/min), and elimination half-life (t1/2) (min). Pharmacokinetic parameters were obtained for each patient in the TAP-DEX group.

\section{Pharmacodynamic Assessments}

Intraoperatively, hemodynamic vitals, including noninvasive blood pressure and heart rate, were recorded before the administration of TAP block (baseline) and at $3,60,90,120,150$, and $180 \mathrm{~min}$ afterward.
Postoperative assessments included hemodynamic vitals (non-invasive blood pressure, heart rate, ventilatory frequency, and peripheral arterial oxygen saturation) recorded at admission to the SICU (baseline), and 2, 4, $6,8,12,18$, and $24 \mathrm{~h}$ postoperatively. The sedation score ( 0 , awake; 1 , easily aroused; 2 , awake after verbal stimulation; 3, awake after tactile stimulation; and 4, not arousable) and the visual analog pain score at rest and during movement (on coughing) were recorded at the same time points. The time to first use of the IV-PCA device and the total consumption of the IV- PCA morphine dose in the first $24 \mathrm{~h}$ postoperatively were also recorded. Perioperative adverse events, such as nausea, vomiting, itching, hypotension, bradycardia, and respiratory depression, were recorded.

\section{Statistics}

Power of the Study

The primary outcome of this study was the plasma concentration of dexmedetomidine. Secondary outcomes were calculated pharmacokinetic parameters for dexmedetomidine,

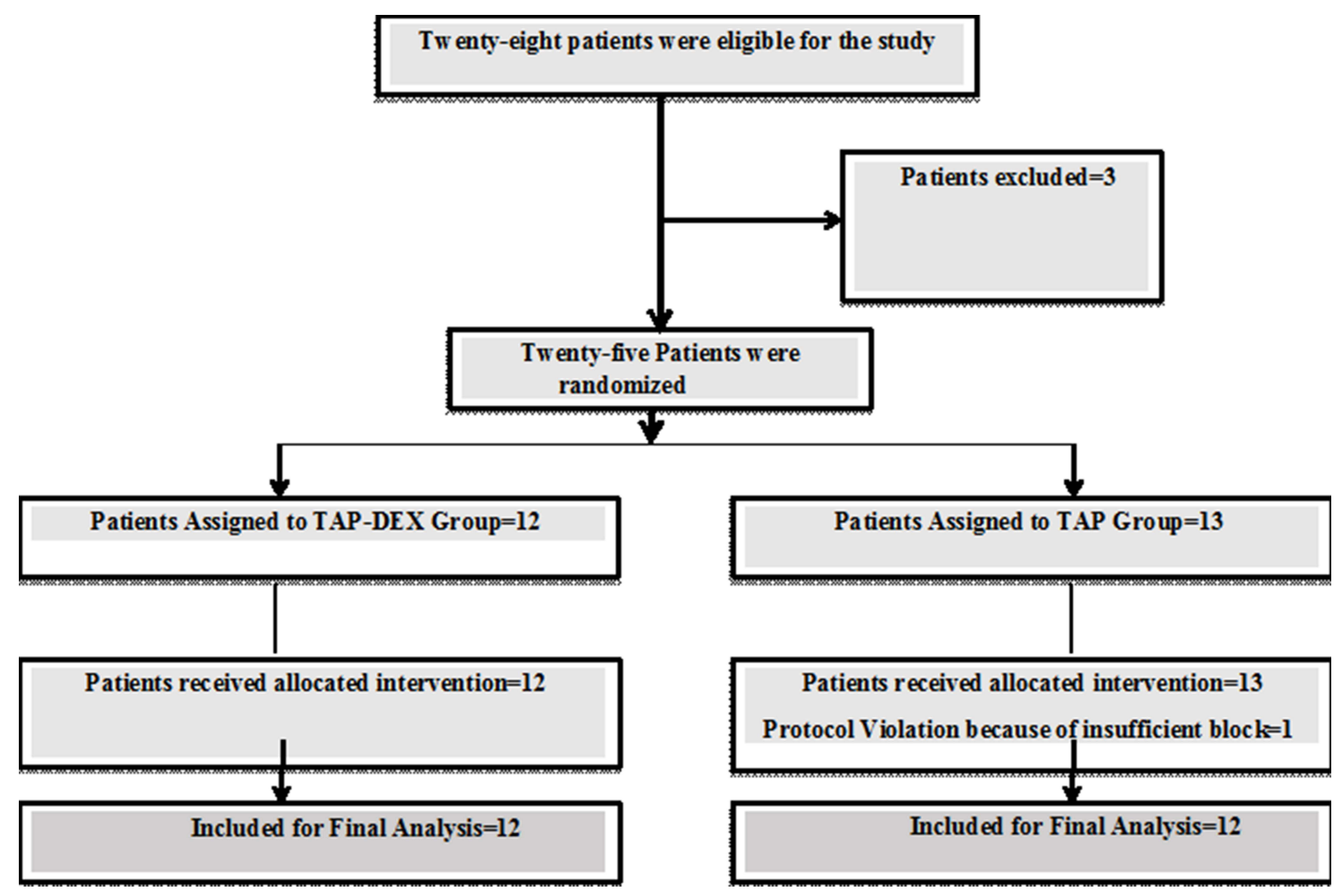

Figure I Participant Flow chart showing that twenty-eight patients were eligible for this study, 3 patients did not meet selection criteria and a patient was excluded. Twentyfour patients (TAP-DEX group $n=12$, TAP group $n=12$ ) completed the study. Abbreviations: TAP, transversus abdominis plane; DEX, dexmedetomidine. 
hemodynamic vitals, postoperative pain profile, sedation score, and perioperative adverse effects. Using the G-Power calculator 3.1.9. $7^{18}$ for the determination of sample size, 12 patients were needed in the TAP-DEX group to study dexmedetomidine pharmacokinetics based on a priori analysis with a type I error of 0.05 , power of 0.8 , and effect size of 0.8 . Fourteen patients were enrolled in the TAP-DEX group to compensate for dropouts, and an equal number was enrolled in the TAP group to study the pharmacodynamics of dexmedetomidine.

\section{Statistical Tests}

Data were collected and processed using SPSS version 20 (SPSS Inc., Chicago, IL, USA). Continuous data were checked for normality by visual inspection of histograms and by the Shapiro-Wilk test. Continuous data are presented as mean $( \pm \mathrm{SD})$ if normally distributed and as median (and range) if not normally distributed. Categorical data were expressed as numbers and frequencies (\%) and analyzed using the chi- square or Fisher's exact test, as appropriate. For normally distributed data, Student's $t$-test and paired Student's $t$-test were used for the analysis of independent and paired samples, respectively. For abnormally distributed and ordinal data, the Mann-Whitney $U$-test and Wilcoxon signed-rank test were used for the analysis of independent and paired samples, respectively. Statistical significance was set at $\mathrm{P}<0.05$.

\section{Results}

\section{Participant Flow}

Twenty-eight patients were eligible for this study, of whom three did not meet our selection criteria, and one patient was excluded due to insufficient TAP block. Twenty-four patients (TAP-DEX group, $n=12$; TAP group, $n=12$ ) completed the blood sampling, pharmacokinetic, and pharmacodynamic assessments and were subjected to statistical analysis (Figure 1).

Table I Patients' Demographics and Clinical Data

\begin{tabular}{|c|c|c|c|}
\hline & $\begin{array}{l}\text { TAP-DEX Group } \\
(n=12)\end{array}$ & $\begin{array}{l}\text { TAP Group } \\
\qquad(n=12)\end{array}$ & P-value \\
\hline Age (years) & $53.08 \pm 9.6$ & $52.58 \pm 8.54$ & 0.894 \\
\hline \multicolumn{4}{|l|}{ Sex } \\
\hline Male/ Female & $5 / 7$ & $7 / 5$ & 0.414 \\
\hline Weight (Kg) & $76.92 \pm 8.43$ & $76.33 \pm 7.98$ & 0.863 \\
\hline Height $(\mathrm{cm})$ & $165.08 \pm 6.71$ & $168.00 \pm 5.44$ & 0.255 \\
\hline BMI $\left(\mathrm{Kg} / \mathrm{m}^{2}\right)$ & $28.47 \pm 4.81$ & $27.09 \pm 3.08$ & 0.412 \\
\hline \multicolumn{3}{|l|}{ Diagnosis } & \multirow{3}{*}{0.682} \\
\hline Cancer bladder & 6 & 7 & \\
\hline Cancer uterus & 6 & 5 & \\
\hline \multicolumn{4}{|l|}{ ASA Class } \\
\hline ASA I/II & 9/3 & $8 / 4$ & 1.000 \\
\hline Serum albumin $(g / L)$ & $44.47 \pm 3.30$ & $44.73 \pm 2.98$ & 0.844 \\
\hline Duration of surgery (min.) & $173.00 \pm 11.01$ & $173.92 \pm 17.89$ & 0.881 \\
\hline Duration of anesthesia (min.) & $182.00 \pm 11.01$ & $186.08 \pm 21.13$ & 0.559 \\
\hline Time to first request for IV- PCA morphine (h). & $11.3 \pm 3.12$ & $9.0 \pm 4.69$ & 0.213 \\
\hline Total IV- PCA morphine consumption dose (mg) & $7.4 \pm 3.24$ & $11.5 \pm 4.46$ & 0.033 \\
\hline \multicolumn{4}{|l|}{ Postoperative adverse events: } \\
\hline -Nausea. & 2 & 4 & NA \\
\hline -Vomiting. & 1 & 4 & \\
\hline
\end{tabular}

Notes: Data presented as mean $( \pm S D)$ and number of patients. P-value is significant if $<0.05$.

Abbreviations: ASA, American Society of Anesthesiologists; PCA, patient controlled analgesia; NA, not applicable. 


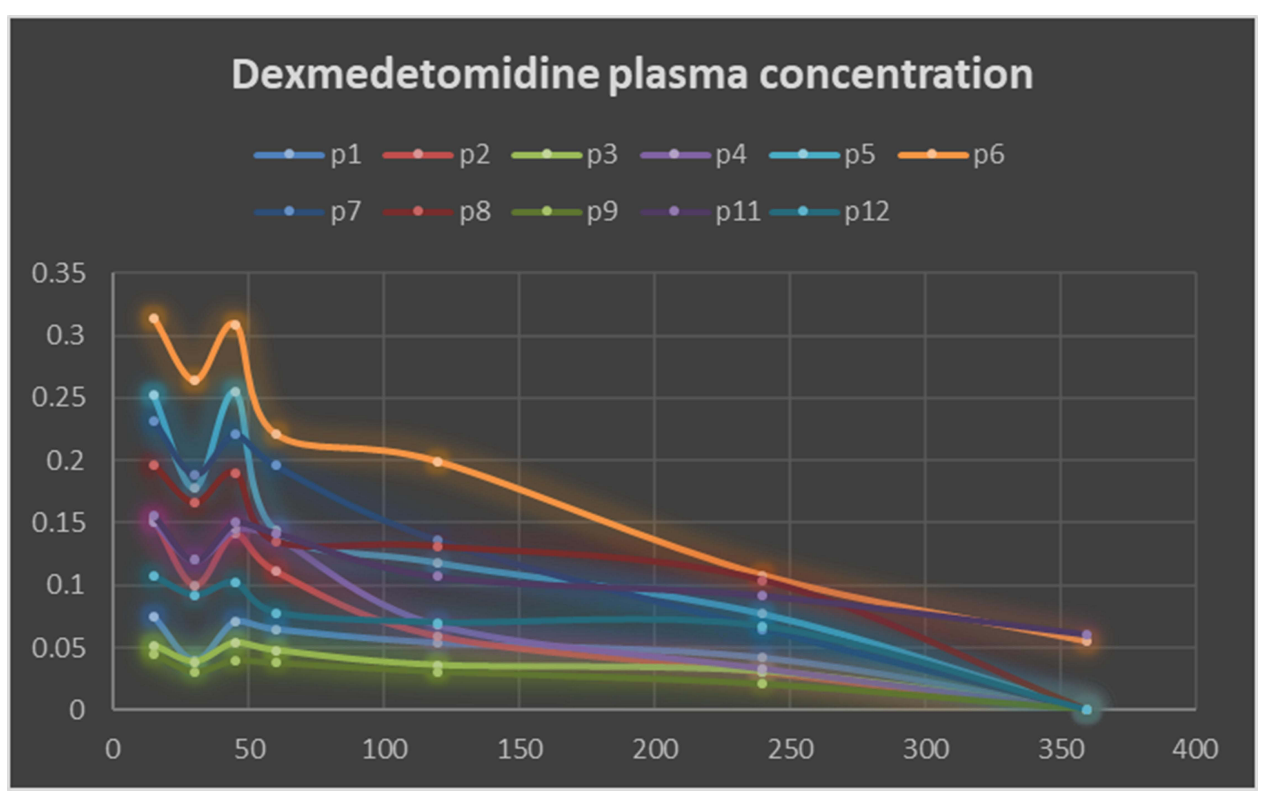

Figure 2 Dexmedetomidine plasma concentration versus time after its administration in transversus abdominis plane block. The mean dexmedetomidine peak plasma concentration (Cmax) was $0.158 \pm 0.085$ (range: $0.045-0.31) \mathrm{ng} / \mathrm{mL}$. Repeated assessments did not detect dexmedetomidine in the plasma of patient no. 10.

Abbreviation: P, patient.

\section{Baseline Data}

The demographic and operative characteristics of the patients were matched between the two groups $(\mathrm{P}>0.05)$ (Table 1).

\section{Primary Outcome}

Dexmedetomidine was detected in the plasma of 11 patients after its administration as an adjuvant to bupivacaine in the TAP block in the TAP-DEX group. Repeated assessments did not detect dexmedetomidine in the plasma of patient no. 10. The dexmedetomidine plasma concentration versus time data for the studied patients are presented in Figure 2. The mean Cmax of dexmedetomidine was $0.158 \pm 0.085 \mathrm{ng} / \mathrm{mL}$ (range, $0.045-0.31 \mathrm{ng} / \mathrm{mL}$ ). The median of Tmax was 15 min (range, 15-45 min). The calculated pharmacokinetic variables of locally administered dexmedetomidine are shown in Table 2.

Table 2 Pharmacokinetics of Dexmedetomidine Administered in TAP Block

\begin{tabular}{|c|c|c|c|c|c|c|c|c|c|c|c|c|}
\hline Item & $\mathbf{P I}$ & $\mathbf{P 2}$ & P3 & P4 & P5 & P6 & P7 & P8 & P9 & PII & PI2 & $\begin{array}{l}\text { Descriptive } \\
\text { Statistics }\end{array}$ \\
\hline $\operatorname{Tmax}$ (min.) & 15 & 15 & 45 & 15 & 45 & 15 & 15 & 15 & 15 & 15 & 15 & $15(14-45)$ \\
\hline $\mathrm{Cmax}(\mathrm{ng} / \mathrm{mL})$ & 0.08 & 0.15 & 0.05 & 0.15 & 0.26 & 0.31 & 0.23 & 0.19 & 0.045 & 0.16 & 0.11 & $0.158(0.086)$ \\
\hline tl/2_Lambda_z (min) & 291.39 & 90.09 & 256.96 & 88.96 & 198.66 & 129.36 & 112.9873 & 456.89 & 209.96 & 257.81 & 893.19 & $\begin{array}{l}209.96 \\
(88.96-893.19)\end{array}$ \\
\hline AUCall (ng/mL*min) & 15.13 & 18.98 & 10.94 & 21.53 & 35.54 & 55.76 & 37.02 & 37.61 & 8.48 & 36.05 & 21.78 & $27.16(14.35)$ \\
\hline AUCINF (observed)(ng/mL*min) & 30.26 & 21.08 & 20.57 & 23.79 & 52.98 & 66.03 & 43.72 & 99.93 & 13.58 & 58.73 & 104.09 & 48.61 (3I.44) \\
\hline AUCINF (observed)/D ( $\mathrm{min} / \mathrm{L})$ & 0.43 & 0.30 & 0.29 & 0.34 & 0.76 & 0.94 & 0.62 & 1.43 & 0.19 & 0.84 & 1.49 & $0.69(0.45)$ \\
\hline Vz (observed)/F (L) & 972.35 & 431.59 & 1261.72 & 377.67 & 378.65 & 197.86 & 261.02 & 461.76 & 1561.82 & 443.29 & 866.53 & $\begin{array}{l}443.29 \\
(197.86-1561.82)\end{array}$ \\
\hline $\mathrm{Cl}$ (observed)/F (L/min) & 2.31 & 3.32 & 3.40 & 2.94 & 1.32 & 1.06 & 1.60 & 0.70 & 5.16 & 1.19 & 0.67 & $2.15(1.4 I)$ \\
\hline Dose of DEX per patient $(\mu \mathrm{g})$ & 80 & 70 & 80 & 90 & 75 & 70 & 70 & 68 & 90 & 80 & 80 & $76.92 \pm 8.43$ \\
\hline
\end{tabular}

Note: Normally distributed data presented as mean (SD) and not normally distributed data presented as median (range).

Abbreviations: TAP, transversus abdominis plane; Cmax, maximum plasma concentration; tmax, time to reach Cmax; AUCall, area under the concentration-time curve from time zero to the last measurable sampling time point; AUCinf, AUC from time zero to time infinity maximum plasma concentration Cmax; V/f, apparent volume of distribution; $\mathrm{CL} / \mathrm{f}$, apparent clearance; $\mathrm{tI} / 2$, elimination half-life. 

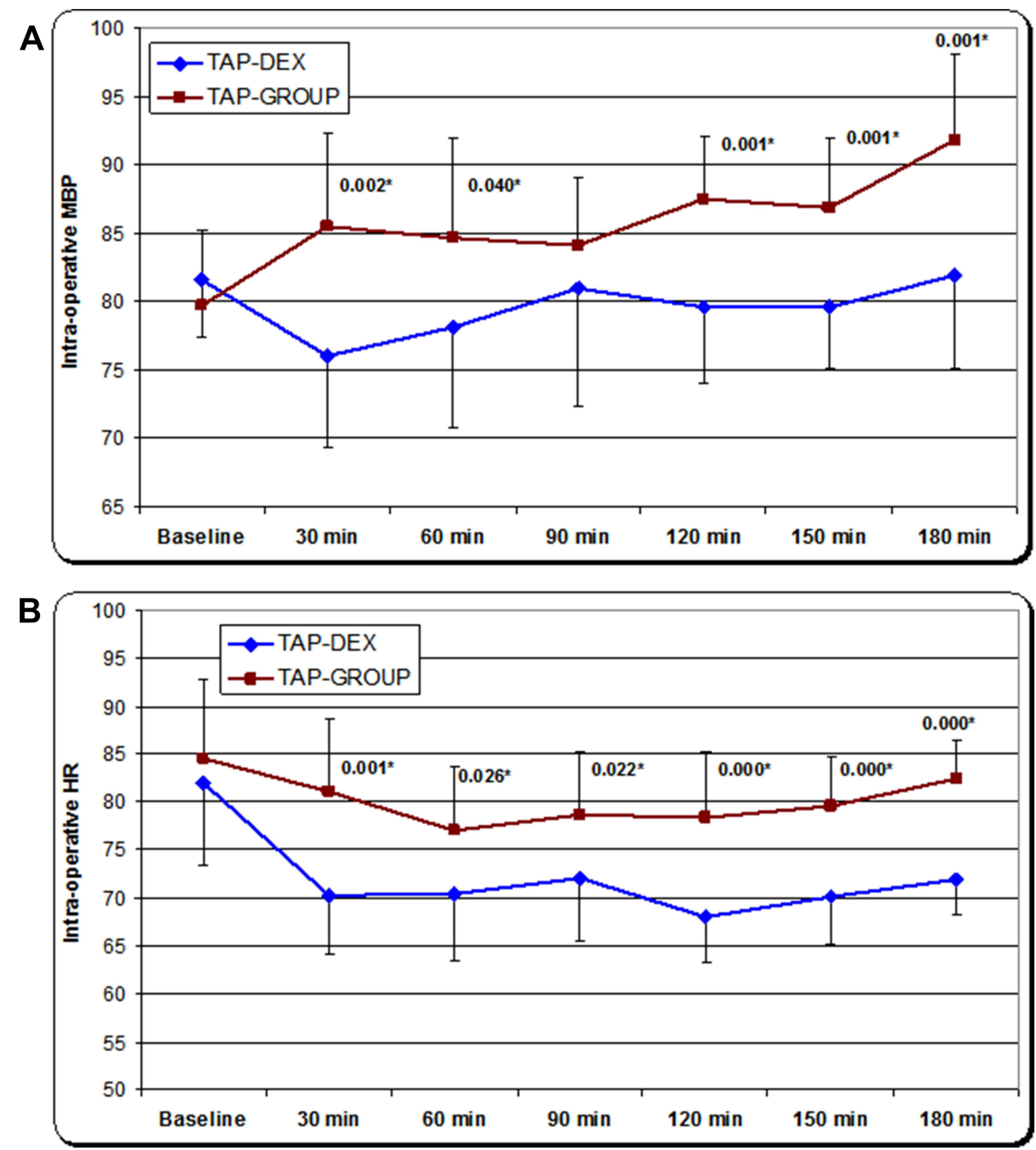

Figure 3 (A) Mean intraoperative non-invasive arterial blood pressure. *Significant decrease in the mean arterial blood pressure throughout the procedure in the TAP-DEX group. (B) Mean intraoperative heart rate. *Significant decrease in the mean heart rate throughout the procedure in the TAP-DEX group.

Abbreviations: TAP, transversus abdominis plane; DEX, dexmedetomidine.

\section{Secondary Outcomes}

Intraoperatively, patients who received dexmedetomidine as an adjuvant to bupivacaine in the TAP block (TAP-DEX group) showed significantly lower mean arterial blood pressure and heart rate after the administration of dexmedetomidine and throughout the operative procedure compared to those who received bupivacaine alone (TAP group) (Figure 3A and $\mathrm{B}$ ).

Postoperatively, upon admission to the SICU and at 2 $\mathrm{h}$ postoperatively, the mean arterial blood pressure and heart rate values were significantly lower in the TAPDEX group than in the TAP group, with no significant differences between the two groups at other time points (Figure 4A and B). The postoperative sedation score, ventilatory frequency, and peripheral arterial oxygen saturation did not show significant differences between the two groups at any time point in this study (Tables 3-5).

From 2 to $8 \mathrm{~h}$ postoperatively, the VAS scores at rest and during movement were significantly lower in the TAPDEX group, with no significant differences between the two groups at other time points (Figure 5A and B). The mean time to first request for IV-PCA morphine was (11.3 \pm 3.12 vs $9.0 \pm 4.69 \mathrm{~h}, \mathrm{P}=0.213$ ) and the mean total dose of morphine consumption in the first $24 \mathrm{~h}$ postoperatively was $(7.4 \pm 3.24$ vs $11.5 \pm 4.46 \mathrm{mg}, \mathrm{P}=0.033)$ in the TAPDEX and TAP groups, respectively, (Table 1). Except for mild nausea and vomiting, no adverse events were recorded in either group in this study (Table 1). 

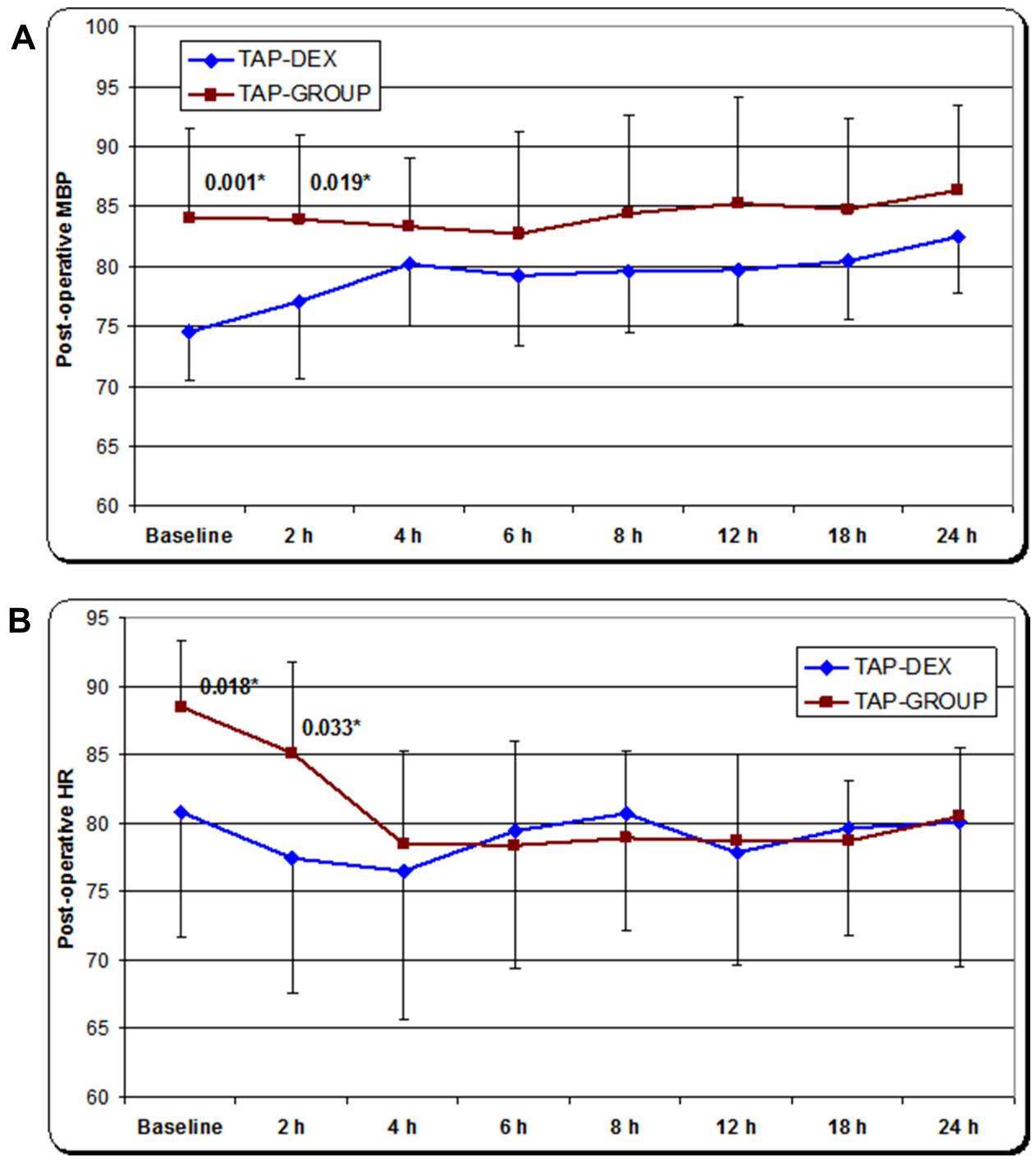

Figure 4 (A) Mean postoperative non-invasive arterial blood pressure. *Significant decrease in the mean postoperative arterial blood pressure in the TAP-DEX group. (B) Mean postoperative heart rate. *Significant decrease in the mean postoperative heart rate in the TAP-DEX group.

Abbreviations: TAP, transversus abdominis plane; DEX, dexmedetomidine.

\section{Discussion}

In this study, we measured the plasma levels of dexmedetomidine locally administered as an adjuvant to bupivacaine in TAP block in patients undergoing lower abdominal cancer surgery. Systemic absorption of dexmedetomidine occurred in 11 out of the 12 patients investigated, and the plasma levels of dexmedetomidine detected ranged from 0.045 to $0.31 \mathrm{ng} / \mathrm{mL}$ (mean, 0.158 $\pm 0.085 \mathrm{ng} / \mathrm{mL}$ ). The addition of dexmedetomidine to bupivacaine in the TAP block enlightened postoperative analgesia for the first $8 \mathrm{~h}$ postoperatively and reduced the postoperative IV-PCA morphine consumption in the first $24 \mathrm{~h}$ postoperatively $(7.4 \pm 3.24$ vs $11.5 \pm 4.46 \mathrm{mg}$; $\mathrm{P}=0.033)$ compared with bupivacaine alone.
The only Food and Drug Administration FDAapproved indication for dexmedetomidine is sedation in adult ICU patients for $<24 \mathrm{~h}$ duration; however, it has been widely used as an adjuvant to local anesthetics to truncal and peripheral nerve blocks. ${ }^{6,9,12-14}$ For TAP block, dexmedetomidine administration, in addition to local anesthetics targeting peripheral nociceptive receptors, has been used successfully for pain control after abdominal surgery. ${ }^{3-6}$ In this study, adding dexmedetomidine to bupivacaine in the TAP block significantly reduced pain scores in the first $8 \mathrm{~h}$ postoperatively and decreased postoperative consumption of IV-PCA morphine. These results are consistent with many similar previous studies, which demonstrated that when 
Table 3 Post-Operative Respiratory Rate (RR)

\begin{tabular}{|c|c|c|c|}
\hline \multirow[t]{2}{*}{$\begin{array}{l}\text { Post-Operative RR } \\
\text { (Breath/Min) }\end{array}$} & $\begin{array}{c}\text { DEX } \\
(n=12)\end{array}$ & $\begin{array}{l}\text { Control } \\
(n=12)\end{array}$ & \multirow[t]{2}{*}{ P-value } \\
\hline & Mean \pm SD & Mean \pm SD & \\
\hline Baseline & $12.33 \pm 0.65$ & $12.17 \pm 0.39$ & 0.455 \\
\hline $2 \mathrm{~h}$ & $12.25 \pm 0.45$ & $12.25 \pm 0.45$ & 1.000 \\
\hline $4 \mathrm{~h}$ & $12.50 \pm 0.52$ & $12.50 \pm 0.52$ & 1.000 \\
\hline $6 \mathrm{~h}$ & $12.33 \pm 0.65$ & $12.33 \pm 0.65$ & 1.000 \\
\hline $8 \mathrm{~h}$ & $12.58 \pm 0.90$ & $12.58 \pm 0.90$ & 1.000 \\
\hline $12 \mathrm{~h}$ & $12.42 \pm 0.79$ & $12.42 \pm 0.67$ & 1.000 \\
\hline $18 \mathrm{~h}$ & $12.25 \pm 0.45$ & $12.25 \pm 0.45$ & 1.000 \\
\hline $24 \mathrm{~h}$ & $12.25 \pm 0.45$ & $12.25 \pm 0.45$ & 1.000 \\
\hline
\end{tabular}

Notes: Data presented asMean \pm SD. TAP-DEX Group, dexmedetomidine group; TAP group, Control; TAP, transversus abdominis plane.

dexmedetomidine is used as an adjuvant to local anesthetics, it yields superior and prolonged analgesia. ${ }^{3-6}$

The analgesic effect of dexmedetomidine, a highly selective $\alpha-2$ agonist, is mainly mediated by binding to central and spinal cord $\alpha 2$-receptors. Therefore, the transmission of pain is suppressed by interneuron hyperpolarization and diminished release of pronociceptive transmitters, including glutamate and substance $\mathrm{P} .{ }^{19}$ In contrast to the sedative effects of $\alpha-2$ agonists, the analgesic effects are still not fully understood and, in part, may be due to the altered perception and diminished levels of

Table 4 Post-Operative Oxygen Saturation $\left(\mathrm{SaO}_{2 \%}\right)$

\begin{tabular}{|l|c|c|c|}
\hline $\begin{array}{l}\text { Post-Operative } \\
\mathrm{SaO}_{2}\end{array}$ & $\begin{array}{c}\text { TAP-DEX } \\
\text { Group }(\mathbf{n = ~ 1 2 )}\end{array}$ & $\begin{array}{c}\text { TAP Group } \\
(\mathbf{n = 1 2})\end{array}$ & \multirow{2}{\text{P-value}}{} \\
\cline { 2 - 3 } & Mean \pm SD & Mean \pm SD & \\
\hline Baseline & $98.75 \pm 0.62$ & $98.75 \pm 0.62$ & 1.000 \\
\hline $2 \mathrm{~h}$ & $98.42 \pm 0.5 \mathrm{I}$ & $98.42 \pm 0.5 \mathrm{I}$ & 1.000 \\
\hline $4 \mathrm{~h}$ & $98.75 \pm 0.62$ & $98.58 \pm 0.90$ & 0.603 \\
\hline $6 \mathrm{~h}$ & $98.42 \pm 0.51$ & $98.42 \pm 0.51$ & 1.000 \\
\hline $8 \mathrm{~h}$ & $98.75 \pm 0.62$ & $98.75 \pm 0.45$ & 1.000 \\
\hline $12 \mathrm{~h}$ & $98.75 \pm 0.62$ & $98.75 \pm 0.62$ & 1.000 \\
\hline $18 \mathrm{~h}$ & $98.75 \pm 0.45$ & $98.75 \pm 0.45$ & 1.000 \\
\hline $24 \mathrm{~h}$ & $98.92 \pm 0.29$ & $98.92 \pm 0.29$ & 1.000 \\
\hline
\end{tabular}

Notes: Data presented as Mean \pm SD. TAP-DEX Group, dexmedetomidine group; TAP group, Control; TAP, transversus abdominis plane.
Table 5 Postoperative Sedation Score

\begin{tabular}{|c|c|c|c|}
\hline \multirow[t]{2}{*}{$\begin{array}{l}\text { Sedation } \\
\text { Score }\end{array}$} & $\begin{array}{c}\text { TAP-DEX Group } \\
(n=12)\end{array}$ & $\begin{array}{l}\text { TAP Group } \\
(n=12)\end{array}$ & \multirow[t]{2}{*}{ P-value } \\
\hline & Median (Range) & Median (Range) & \\
\hline Baseline & $1.0(0.0-1.0)$ & $1.0(0.0-1.0)$ & 1.000 \\
\hline $2 \mathrm{~h}$ & $0.0(0.0-1.0)$ & $0.0(0.0-1.0)$ & 0.623 \\
\hline P-value ${ }^{2}$ & $0.011 *$ & $0.003 *$ & \\
\hline $4 \mathrm{~h}$ & $0.0(0.0-1.0)$ & $0.0(0.0-1.0)$ & 1.000 \\
\hline P-value ${ }^{2}$ & $0.003 *$ & $0.003 *$ & \\
\hline $6 \mathrm{~h}$ & $0.0(0.0-0.0)$ & $0.0(0.0-0.0)$ & 1.000 \\
\hline P-value ${ }^{2}$ & $0.00 I^{*}$ & $0.001 *$ & \\
\hline $8 \mathrm{~h}$ & $0.0(0.0-0.0)$ & $0.0(0.0-0.0)$ & 1.000 \\
\hline P-value ${ }^{2}$ & $0.001 *$ & $0.001 *$ & \\
\hline $12 \mathrm{~h}$ & $0.0(0.0-0.0)$ & $0.0(0.0-0.0)$ & 1.000 \\
\hline P-value ${ }^{2}$ & $0.001 *$ & $0.00 I^{*}$ & \\
\hline $18 \mathrm{~h}$ & $0.0(0.0-0.0)$ & $0.0(0.0-0.0)$ & 1.000 \\
\hline P-value ${ }^{2}$ & $0.00 I^{*}$ & $0.001 *$ & \\
\hline $24 \mathrm{~h}$ & $0.0(0.0-0.0)$ & $0.0(0.0-0.0)$ & 1.000 \\
\hline P-value ${ }^{2}$ & $0.001 *$ & $0.00 I^{*}$ & \\
\hline
\end{tabular}

Notes: Data presented as median (range). TAP-DEX Group, dexmedetomidine group; TAP group, Control; TAP, transversus abdominis plane. *Significant difference when comparing each time point to the base line.

anxiety due to associated decreased release of norepinephrine and opioid-sparing effects. ${ }^{16}$

Angst et al conducted a study on healthy volunteers. ${ }^{20}$ They examined the analgesic effects of different doses of intravenous dexmedetomidine in direct comparison to alfentanil as a $\mu$ receptor agonist. At each level of sedation produced, the authors examined the analgesia level, accomplishing experimental models for heat and electrical pain. Four median step-up plasma concentrations of dexmedetomidine $(0.09,0.24,0.54$, and $1.23 \mathrm{ng} / \mathrm{mL})$ and alfentanil (13.4, 33.8, 67.8, and $126.1 \mathrm{ng} / \mathrm{mL})$ were administered via a computer-controlled infusion. They found that the sedative effects of both drugs were dosedependent. The analgesic efficacy of alfentanil was also dose-dependent; however, dexmedetomidine did not. They concluded that dexmedetomidine causes mild to severe sedation, but it lacks analgesic efficacy for heat and pain in healthy volunteers. ${ }^{20}$ Moreover, comparing dexmedetomidine and remifentanil concerning the respiratory and analgesic effects showed that dexmedetomidine at plasma concentrations of up to $2.4 \mathrm{ng} / \mathrm{mL}$ produced less efficient analgesia than remifentanil. ${ }^{16}$ In this study, the detected dexmedetomidine plasma level ranged from 0.045 to 0.31 

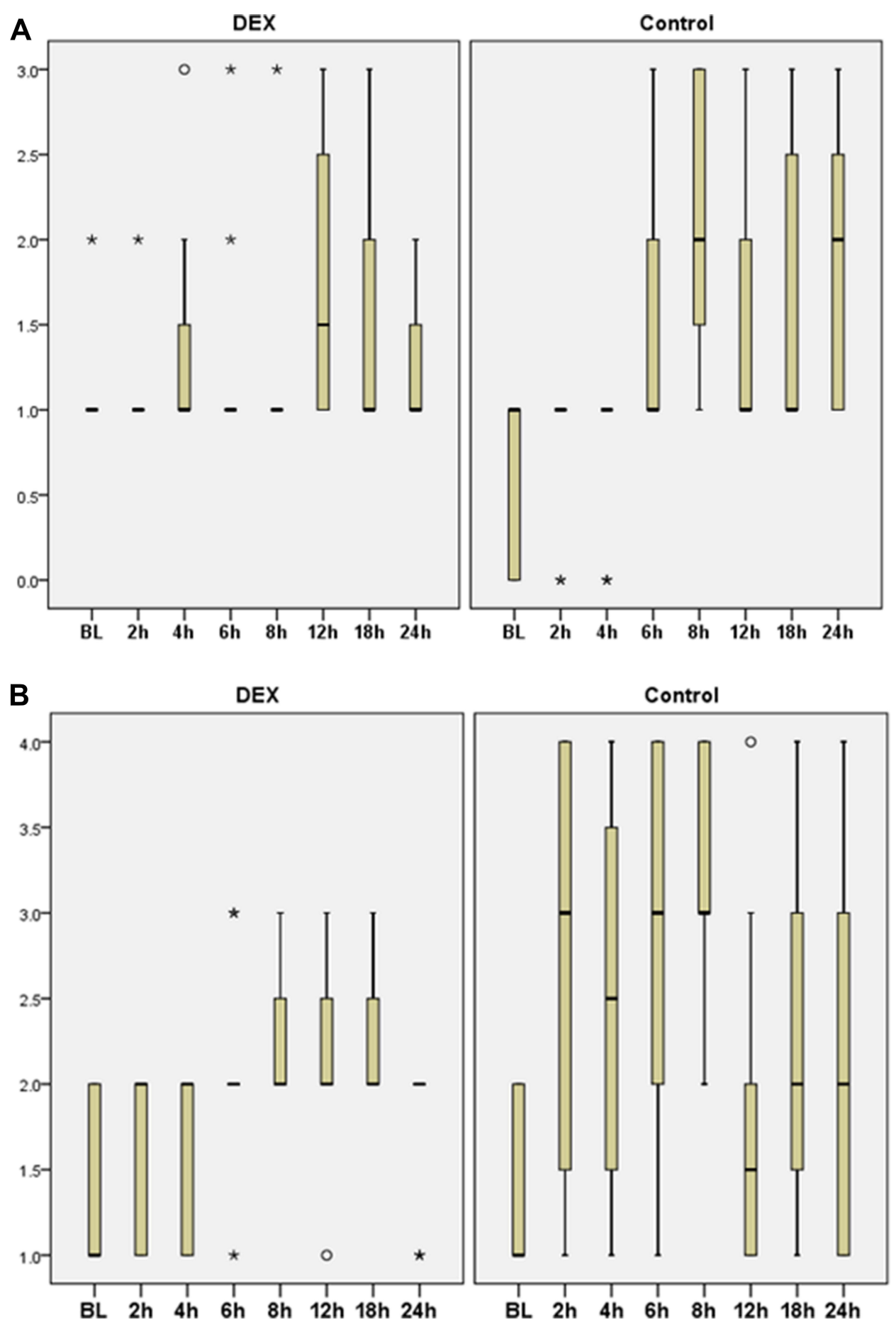

Figure 5 (A) Postoperative visual analogue pain scores (VASR) at rest. Data presented as median (range), *Significant decreased in the VAS in the DEX group compared to control group. (B) Postoperative visual analogue pain scores (VASM) during movement. Data presented as median (range), *Significant decreased in the VAS in the DEX group compared to control group.

Abbreviations: DEX, dexmedetomidine group; Control, bupivacaine group.

$\mathrm{ng} / \mathrm{mL}$ (mean, $0.158 \pm 0.085$ ). These levels are not completely responsible for the analgesic effect that we recorded with locally administered dexmedetomidine, but it might potentiate the local mechanisms of TAP-DEX analgesia.
In contrast, Abdallah et al in their study concluded that both systemic and perineural dexmedetomidine produced comparable analgesia levels after interscalene brachial plexus block. ${ }^{12}$ Other studies reported that IV dexmedetomidine synergistically interacts with regional anesthesia, 
increasing the duration of sensory block by $34 \%$, motor block by $17 \%$, and the time to first request for postoperative analgesia by $53 \% .^{13,21}$ A limitation of this study is that we did not include an IV dexmedetomidine group for our comparisons. The presence of such a group could have enabled us to confirm or declare the role of systemic absorption of locally administered dexmedetomidine in the production of analgesia. Comparing the plasma levels of dexmedetomidine and associated analgesia produced after intravenous and local TAP-dexmedetomidine is deficient, and further studies on this topic are needed.

In this study, we confirmed that systemic absorption of TAP-dexmedetomidine is not uncommon. However, it is unclear whether the plasma levels we detected had the potential to further enhance the analgesia produced by local mechanisms.

As repeated assessments did not detect dexmedetomidine in the plasma of patient no. 10, we are looking forward to conduct a set of genetic studies to find an explanation for its consistent findings.

The plasma levels of dexmedetomidine detected in this study were sufficient to produce an intraoperative decrease in the mean arterial pressure and heart rate $30 \mathrm{~min}$ after its administration compared with patients who received TAP block with bupivacaine only. Consistent with many previous studies, the hemodynamic adverse effects of dexmedetomidine reported in this study were mild and easily managed. $6,22-24$

Systemic absorption of the drug can influence patients' hemodynamics and analgesia and is important for optimum dosing strategies (interactions with other drugs).

Limitations of this study include the small sample size and the absence of an intravenous dexmedetomidine group. As mentioned before, the presence of such a group could have enabled us to estimate the degree and importance of systemic absorption of the locally administered dexmedetomidine.

\section{Conclusion}

In conclusion, systemic absorption of dexmedetomidine administered in TAP blocks is not uncommon. Direct central effects on the locus coeruleus caused by this systemic absorption may play a role in the analgesia produced by TAP-dexmedetomidine in addition to the local mechanisms.

\section{Abbreviations}

DEX, dexmedetomidine; HR, heart rate; MAP, mean arterial pressure; $\mathrm{SaO} 2 \%$, peripheral arterial oxygen saturation; VAS, visual analogue scale; SICU, surgical intensive care units; IV-PCA, intravenous patient controlled analgesia; Cmax, maximum plasma concentration; AUCall, area under the concentration-time curve from time zero to the last measurable sampling time point; AUCinf, AUC from time zero to time infinity maximum plasma concentration Cmax; tmax, time to reach Cmax; V/f, apparent volume of distribution; $\mathrm{CL} / \mathrm{f}$, apparent clearance; $\mathrm{t} 1 / 2$, elimination half-life.

\section{Data Sharing Statement}

We are not planning to share any of the data with anyone.

\section{Acknowledgment}

We are grateful to the operating theatre and SICU staff for their co-operation in data collection.

\section{Funding}

No funding was taken to accomplish this work.

\section{Disclosure}

The authors report no conflicts of interest for this work.

\section{References}

1. Rafi AN. Abdominal field block: a new approach via the lumbar triangle. Anaesthesia. 2001;56:1024-1026. doi:10.1046/j.13652044.2001.02279-40.x

2. Carney J, Finnerty O, Rauf J, Bergin D, Laffey JG, Mc Donnell JG. Studies on the spread of local anaesthetic solution in transversus abdominis plane blocks. Anaesthesia. 2011;66:1023e30.

3. Guo Q, Li R, Wang L, Zhang D, Ma Y. Transversus abdominis plane block versus local anaesthetic wound infiltration for postoperative analgesia: a systematic review and meta-analysis. Int J Clin Exp Med. 2015;8(10):17343-17352.

4. Baeriswyl M, Zeiter F, Piubellini D, Kirkham KR, Albrecht E. The analgesic efficacy of transverse abdominis plane block versus epidural analgesia: a systematic review with meta-analysis. Medicine. 2018;97 (26):e11261. doi:10.1097/MD.0000000000011261

5. Desai N, El-Boghdadly K, Albrecht E. Epidural vs. transversus abdominis plane block for abdominal surgery - a systematic review, meta-analysis, and trial sequential analysis. Anaesthesia. 2020. doi:10.1111/anae.15068

6. Sun Q, Liu S, Wu H, et al. Dexmedetomidine as an adjuvant to local anesthetics in transversus abdominis plane block: a systematic review and meta-analysis. Clin J Pain. 2019;35(4):375-384. doi:10.1097/ AJP.0000000000000671

7. Prabhakar A, Lambert T, Kaye RJ, et al. Adjuvants in clinical regional anesthesia practice: a comprehensive review. Best Pract Res Clin Anaesthesiol. 2019;33(4):415-423. doi:10.1016/j.bpa.2019.06.001

8. Ammar AS, Mahmoud KM, Kasemy ZA. Comparison between adenosine and magnesium sulphate as adjuvants for transversus abdominis plane block: a prospective randomized controlled trial. Minerva Anestesiol. 2018;84(3):304-310. doi:10.23736/S0375-9393.17.11931-0

9. Schnabel A, Reichl SU, Weibel S, et al. Efficacy, and safety of dexmedetomidine in peripheral nerve blocks: a meta-analysis and trial sequential analysis. Eur J Anaesthesiol. 2018;35(10):745-758. doi:10.1097/EJA.000000000000870 
10. Fritsch G, Danninger T, Allerberger K, et al. Dexmedetomidine added to ropivacaine extends the duration of interscalene brachial plexus blocks for elective shoulder surgery when compared with ropivacaine alone: a single-center, prospective, triple-blind, randomized controlled trial. Reg Anesth Pain Med. 2014;39(1):37-47. doi:10.1097/AAP.0000000000000033

11. Pan W, Liu G, Li T, et al. Dexmedetomidine combined with ropivacaine in ultrasound-guided tranversus abdominis plane block improves postoperative analgesia and recovery following laparoscopic colectomy. Exp Ther Med. 2020;19(4):2535-2542. doi:10.3892/etm.2020.8508

12. Abdallah FW, Dwyer T, Chan VWS, et al. IV and perineural dexmedetomidine similarly prolong the duration of analgesia after interscalene brachial plexus block. Anesthesiology. 2016;124:683-695. doi:10.1097/ALN.0000000000000983

13. Abdallah FW, Abrishami A, Brull R. The facilitatory effects of intravenous dexmedetomidine on the duration of spinal anesthesia. Anesth Analg. 2013;117:271-278. doi:10.1213/ANE.0b013e318290c566

14. Kang R, Jeong JS, Yoo JC, et al. Effective dose of intravenous dexmedetomidine to prolong the analgesic duration of interscalene brachial plexus block: a single-center, prospective, double-blind, randomized controlled trial. Reg Anesth Pain Med. 2018;43 (5):488-495. doi:10.1097/AAP.0000000000000773

15. Guo TZ, Tinklenberg J, Oliker R, Maze M. Central alpha 1-adrenoceptor stimulation functionally antagonizes the hypnotic response to dexmedetomidine, an alpha 2-adrenoceptor agonist. Anesthesiology. 1991;75:252-256. doi:10.1097/00000542-199108000-00013

16. Weerink MAS, Struys MMRF, Hannivoort LN, Barends CRM, Absalom AR, Colin P. Clinical pharmacokinetics and pharmacodynamics of dexmedetomidine. Clin Pharmacokinet. 2017;56 (8):893-913. doi:10.1007/s40262-017-0507-7

17. Mohamed SA, Abdel-Ghaffar HS, Hassan NA, et al. Pharmacokinetics and pharmacodynamics of 3 doses of oral-mucosal dexmedetomidine gel for sedative premedication in women undergoing modified radical mastectomy for breast cancer. Anesth Analg. 2021;132(2):456-464. PMID: 32889844. doi:10.1213/ ANE.0000000000005108
18. Faul F, Erdfelder E, Lang AG, Buchner A. G*Power 3: a flexible statistical power analysis program for the social, behavioral, and biomedical sciences. Behav Res Methods. 2007;39:175-191. doi:10.3758/BF03193146

19. Vuyk J, Sitsen E, Reekers M, et al. Intravenous anesthetics. In: Miller RD, Cohen NH, Eriksson LI, editors. Miller's Anesthesia. 8th ed. Amsterdam: Elsevier; 2015:854-859.

20. Angst MS, Ramaswamy B, Davies MF, Maze M. Comparative analgesic and mental effects of increasing plasma concentrations of dexmedetomidine and alfentanil in humans. Anesthesiology. 2004;101(3):744-752. doi:10.1097/00000542-200409000-00024

21. Wu -H-H, Wang H-T, Jin -J-J, et al. Does dexmedetomidine as a neuraxial adjuvant facilitate better anesthesia and analgesia? A systematic review and meta-analysis. PLoS One. 2014;9:e93114. doi:10.1371/journal.pone.0093114

22. Chamadia S, Pedemonte JC, Hobbs LE, et al. A pharmacokinetic and pharmacodynamic study of oral dexmedetomidine. Anesthesiology. 2020;133(6):1223-1233. doi:10.1097/ALN.0000000000003568

23. Bansal P, Garg S. Effect of adding dexmedetomidine to local anesthetic agents for transversus abdominis plane block: a meta-analysis. Clin $J$ Pain. 2019;35(10):844-854. PMID: 31259745. doi:10.1097/ AJP.0000000000000742

24. Aksu R, Patmano G, Biçer C, Emek E, Çoruh AE. Eficácia de bupivacaína e associação com dexmedetomidina em bloqueio do Plano transverso abdominal guiado por ultrassom na dor após cirurgia abdominal [Efficiency of bupivacaine and association with dexmedetomidine in transversus abdominis plane block ultrasound guided in postoperative pain of abdominal surgery]. Rev Bras Anestesiol. 2018;68(1):49-56.
Journal of Pain Research

\section{Publish your work in this journal}

The Journal of Pain Research is an international, peer reviewed, open access, online journal that welcomes laboratory and clinical findings in the fields of pain research and the prevention and management of pain. Original research, reviews, symposium reports, hypothesis formation and commentaries are all considered for publication. The manuscript management system is completely online and includes a very quick and fair peer-review system, which is all easy to use. Visit http:// www.dovepress.com/testimonials.php to read real quotes from published authors. 